\title{
Research on the Interference Trend of National Taxation with Price and Inflation
}

\author{
Shufeng Wang, Junwei Han \\ College of Accounting, Heilongjiang Bayi Agriculture University, Daqing, China \\ Email: wsf630817@163.com
}

How to cite this paper: Wang, S.F. and Han, J.W. (2018) Research on the Interference Trend of National Taxation with Price and Inflation. Open Journal of Social Sciences, 6, 156-167. https://doi.org/10.4236/jss.2018.63011

Received: February 9, 2018

Accepted: March 23, 2018

Published: March 26, 2018

Copyright ( $) 2018$ by authors and Scientific Research Publishing Inc. This work is licensed under the Creative Commons Attribution International License (CC BY 4.0).

http://creativecommons.org/licenses/by/4.0/

\section{(c) (i) Open Access}

\begin{abstract}
In view of the objective reality that the market prices stay high in recent years, inflation which continues to rise is not effectively inhibited, combined with the previous economic circles who attributed the reasons to inflation for commodity supply and demand, the issuance of money and neglect the role of tax factors led to national governance inflation decision-making that is limited by the phenomenon. By means of comparative analysis, Granger causality analysis and Augmented Dickey-Fuller test, we dissect the external disturbance and endogenous factors of influencing inflation, select the 2001-2016 tax index and CPI index and make an empirical research of the interference from government taxation to price and inflation trends and strength. It is approved there is single causal relationship between tax and price rising, and sums up that government taxation can promote inflation, but inflation can't lead to tax rising. Of course, this conclusion can also provide theoretical support for national governance of inflation.
\end{abstract}

\section{Keywords}

National Tax, Inflation, Turnover Tax, Single Causal Relationship

\section{Introduction}

Over the years, the international and domestic academic theorists have argued that taxation is the cost factor that leads to rising prices, but have ignored the objective facts that the price tax has no affect on the cost but can lead to rising prices and then cause inflation [1]. People did not reveal tax as a direct element of price or some ideological concerns that affected the decision-making ideas of the country to curb prices and govern inflation through the taxation. Because of this, it has damaged the government's economic prestige. In academic theory, it is generally believed that inflation depends on the commodity market in short 
supply, the government overdraft to the bank including additional currency and excessive import surplus and other factors. Some people even think that inflation has a tax function. Especially in recent years, China's tax revenue was often rapidly increasing several times to GDP. Some scholars believe that the rising prices are the important reason to promoting tax revenue growth [2]. But the practice shows that if the tax policy is stable, then the tax revenue growth is only the result of inflation during the rising prices. Only in the areas where economic development and quality are improved, can taxation produce real growth which is healthy. When the inflation is caused by the supply and demand changes and the government's issuance of money emerges, the tax also can become an important means to regulate the price of goods and services and control inflation.

\section{Research Background}

For a long time, both domestic and international academic circles think that the supply of goods is in short supply, and the excessive issuance of currencies and trade surpluses by the state are the key elements of rising prices and inflation [1]. Some scholars think that inflation has the function of promoting tax revenue growth. Especially in recent years, tax revenue in China often grows several times faster than GDP. The important reason is that price inflation and inflation (hereinafter referred to as "inflation") result in [2]. However, under the circumstance that the market supply and demand are in balance or oversupply, the state does not issue any additional currency and the import and export trade surpluses are not great, the market price still rises or even prolonged inflation persists. At this point, the traditional theoretical point of view cannot explain this special economic phenomenon, the government to stabilize prices and control inflation is also embarrassed dilemma. In fact, in the past, experts and scholars have ignored the core issue of inflation is the "price", and the internal factors that determine the price in addition to cost, cost and profit accounting elements, there is a business and the market cannot be predicted and control the "tax" Elements. In the premise of the relevant accounting elements unchanged, the tax increase is the result of price increases. Therefore, inflation will not create a real increase in tax revenue, but can only say that the tax revenue contains the "water" of currency devaluation. However, if tax reform is to be carried out in a period of steady economic development, such as the introduction of new taxes, the increase of tax rates or the expansion of tax collection, the risks of price increases and inflation will be buried while ensuring a substantial increase in tax revenues. The state can only increase and reform supply-side reform through structural tax cuts in order to curb and eliminate inflation. Based on this particular understanding and understanding, the author chose this proposition to conduct his research.

\section{The Interferential Factors of Price and Inflation}

The change of supply and demand is an important external factor of price fluc- 
tuation again and again. It forms inflation when the price increases so blindly that the commodity value is seriously deviate from the price. However, if the inflation happens under the stable circumstances of the goods and services or some other factors, it is because the factors power except supply and demand stimulate stimulus seriously to the changes in commodity prices.

\subsection{The External Interference Factors of Inflation}

Economists generally believe that the market price deviates from the commodity value and government additional currency is the most important external factors leading to inflation [3]. It is the consumption policies which the governments carry out to promoting economic growth, excessive issuance of money, restrictions on supply and imports that lead to the shortage of commodity are bound to stimulate inflation beside the price of commodity and service. Of course, a specific period of time for people to focus on the purchase and reserve of goods and services so that promoting the expansion of consumption, causing monetary tightening, and also boosting inflation. In addition, there are "tend to consumption" which caused by advertising guidance and business speculation promotes the increasing demand of individual commodity and services, finally lead to price rising. For example, around 2010 someone said that "the green beans cure all kinds of diseases" which set off a boom of green beans, in two consecutive years the national green beans market was tension, the price of green beans reached the peak of the history that had a serious impact on the normal living needs of residents. In addition, the behavior of abnormal consumer and bad businessmen who drove up the price also can cause inflation.

\subsection{The Internal Factors of Inflation}

The economists generally recognized that the price of the factor determines the theoretical thought. It means that the price of goods and services at the industrial level is determined by different factors such as labor, land, capital and other related production processes, these factors determine the price of social products and their changes. When the production factors further achieve its price through the transaction behavior of commodity or service, it has the formation of the distribution activities of wages, rent and profit and other income elements, and the price factors under the income distribution [4].

Obviously, the traditional price theory only takes into account of the cost and profit factors, ignoring the impact of national tax distribution. The marketing theory believes that whatever goods and services must achieve to the industry advance value of assets repurchase and the expected income recovery through the market sales behavior. The price factors of repurchase and recovery including production costs, circulation costs, tax, profit and so on, it can express by the formula:

Goods and services prices $=$ cost + expense + tax + profit

The cost, expense, tax and profit in the formula are directly related to the 
price, and it is bound to cause the price of goods and services fluctuation whichever changes in the elements. In the market economy conditions, enterprises are independent subjects facing the fierce competition in the same field, they make all efforts to control prices to stabilizing the market purchasing, strive to reducing costs and the ways of expense and ensure adequate profit space. In the state of short supply, the market will drive the business managers to enhance the profit-induced, so as to promote commodity prices rising. Profit can become an important factor to inflation during supply and demand tension period; but in the supply and demand balance, enterprises have no reason to get more profits through increasing price to deliberately undermine consumer trust or damage to loyal customers. This shows that the cost, expense and profit originate from the main body of the production and operation are not the dominant factors of rising prices and inflation. Then, to explain the internal reasons to the emergence of rising prices led to inflation continue rising in the fact that the central government has not raised the money for many years, the balance of supply and demand of commodity services has even experienced a serious oversupply of the market environment, the target can only be located in the tax indicators.

Since the tax is the component indicators of price, it cannot deny the impact of tax changes on prices, and also admit tax rising will promote price rising and inflation. With the continuous development of market economy and accounting standards line with international standards, a variety of price elements are active in the accounting statements, and generally concerned a lot by the community. One of the most important is a variety of transfer tax including the value-added tax-based, supplemented by consumption tax. The taxes paid by the merchants are all "pass" to the residents by price. These further show that the state will directly lead to fluctuations in the price of goods and services when carry out some transfer of tax policy adjustments each time. In China, the turnover tax accounts for about $60 \%$ of the total tax revenue, indicating that the tax revenue mainly from the economic operation of the link, it also has very strong power to the price adjustment.

\section{Data Source and Analysis Framework}

Although the purpose of the government to increase taxes is not to create inflation, it will be further intensified inflation objectively, even to adding new taxes for the production and circulation areas in sudden or increasing tax rate drastically, it is bound to directly lead to inflation. Whether this view is established can be further verified by empirical analysis.

\subsection{Data Source}

The research data mainly come from the "China Statistical Yearbook" (including the combined edition) issued by the National Bureau of Statistics of China from 2001 to 2017 and the "National Data" released by the website of the National Bureau of Statistics. The index data of the tax revenue of the relevant countries 
are mainly from the Ministry of Finance, "General Administration of Taxation" and "Tax Bulletin" issued by the State Administration of Taxation.

\subsection{Analysis Framework}

The core problem of this study is to prove that there is a causal relationship between taxation ( $\mathrm{x}$ ) and inflation (y), which depends on the variance of the best least squares forecasting that contains all the indicators of information in the past several years. To this end, it is appropriate to take the Clive WJ Granger causality test. The principle is under the time series, if the information of the variables $\mathrm{X}$ and $\mathrm{Y}$ is complete, the prediction result of $\mathrm{Y}$ to $\mathrm{X}$ is better than that based on the historical index of $Y$. That is, the variable $\mathrm{X}$ is more effective in explaining the future variation of the variable $\mathrm{Y}$. It is assumed that the variable $\mathrm{X}$ is the Granger cause that causes the variable Y. The main application of the method is as follows:

\subsubsection{Smoothness Regression Test}

The regression test is to test the smoothness of time series. By detecting the unit root, it is necessary to prevent false regression or "pseudo-regression" in the prediction process and use the ADF test method to carry out the unit root (Unit Root Test) [5]. First, we establish a "constrained regression" of $y_{t-1}, y_{t-2}, \cdots, y_{t-q}$ for all lagged terms of " $y$ " to $y$ without " $x$ ", and obtain the residual squares and $R S S_{R}$; then establish a "unconstrained regression" of $x_{t-1}, x_{t-2}, \cdots, x_{t-s}$ for all lagged items from " $x$ " to " $y$ ", and reach the unconstrained residual squares and " $R S S_{U R}$ " according to this regression. Assuming that the predictions for each variable of " $y$ " and " $x$ " are all included in the time series, the following regression is required:

$$
\begin{aligned}
& y_{t}=\sum_{i=1}^{q} \alpha_{i} x_{t-i}+\sum_{j=1}^{q} \beta_{j} y_{t-j}+u_{1 t} \\
& x_{t}=\sum_{i=1}^{s} \lambda_{i} x_{t-i}+\sum_{j=1}^{s} \delta_{j} y_{t-j}+u_{2 t}
\end{aligned}
$$

Assuming that the white noise $u_{1 t}$ and $u_{2 t}$ are uncorrelated, y in the (1) current state is related to " $y$ " itself and the past value of " $x$ ". Then we obtain the null hypothesis like this, $\mathrm{H}_{0}: \alpha_{1}=\alpha_{2}=\cdots=\alpha_{q}=0$, it follows the $\mathrm{F}$ distribution that the degrees of freedom are " $q$ " and " $(n-k)$ ". The null hypothesis of (2) is $\mathrm{H}_{0}$ : $\delta_{1}=\delta_{1}=\cdots=\delta_{s}=0 \quad[5]$.

\subsubsection{Granger Causality Test}

Sequence smoothness is an important prerequisite for the application of Granger test. If the data is non-stationary sequence, there will be pseudo-regression, which affects the judgement of the causal relationship among variables. It is necessary to use each sequence of single order to further carry out cointegration test to deter mine the time series of data generation process. We set " $n$ " is the sample size, " $q$ " is equal to the number of hysteresis items " $\vec{x}$ ", it means there are 
some parameters to be estimated in the constrained regression equation, and " $k$ " is the number of parameters to be estimated in the unconstrained regression.

Use $F$ to test null hypothesis: $F=\frac{\left(R S S_{R}-R S S_{U R}\right) / q}{R S S_{U R} /(n-k)}$

If the $F$ value calculated at the selected significance level $\alpha$ exceeds the critical $F a$ value (0.05), the null hypothesis is rejected so that the lagged item " $x$ " belongs to this regression, indicating that " $x$ " is the reason for " $y$ "; if use " $y$ " for an exchange of " $x$ ", you can test the reason why $y$ is $x$.

\subsection{Granger Causality Analysis}

According to $\mathrm{x}-\mathrm{y}$ model analysis and co-integration test, $\mathrm{x}$ and $\mathrm{y}$ may produce three causal relations.

\subsubsection{No Causal Relationship}

If the hysteretic coefficient estimate of " $x$ " and " $y$ " in Formula (1) (2) are zero holistic and significant in statistics, it means that " $x$ " and " $y$ " are independent each other, and there is no causal relationship between " $x$ " and " $y$ ".

\subsubsection{Single Causal Relationship}

If the hysteretic coefficient estimate of " $x$ " in Formula (1) isn't zero holistic and significant in statistics, the coefficient estimate of " $y$ " in Formula (2) is zero holistic and significant in statistics, " $x$ " is the reason for the change of " $y$ ", this explains there is single causal relationship from " $x$ " to " $y$ "; If the coefficient estimate of " $y$ " in Formula (2) isn't zero holistic and significant in statistics, the coefficient estimate of " $X$ " in Formula (1) is zero holistic and significant in statistics, " $y$ " is the reason for the change of " $x$ ", so there is single causal relationship from " $y$ " to " $x$ ".

\subsubsection{Mutual Causal Relationship}

If the coefficient estimate of " $x$ " and " $y$ " in Formula (1) (2) aren't zero holistic and significant in statistics, it means there is mutual causal relationship between " $x$ " and " $y$ ", not only there is single causal relationship from " $x$ " to " $y$ ", but also single causal relationship from " $y$ " to " $x$ ".

\section{The Empirical Analysis of Causal Relationship between Tax and Inflation}

While academics recognize the relationship among taxation, rising prices and inflation, most scholars believe that taxing can boost prices by increasing manufacturing costs and potentially boosting inflation. For example, since May 10, 2015 the ad valorem duty rate changed from $5 \%$ to $11 \%$ in the cigarette wholesale link, and added fixed consumption tax each of 0.005 RMB. Then the State Tobacco Monopoly Bureau increased all cigarettes on the wholesale price of $6 \%$ and the retail price of not less than $10 \%$, just the same as the newly adjusted tax rate. So, people think it was the new cigarette consumption tax that increased in 
the cost of cigarettes and promoted its price rising [5] [6]. But this view cannot explain the value-added tax as a "price tax" does not affect the cost and profits of goods and services, but why it will also affect the commodity prices and even lead to inflation. This shows that all indirect taxes and price were in the same direction, regardless of whether to act on the costs, they are all belong to the endogenous factors of price, inflation and important variables.

\subsection{Indicator Establishment and Data Selection}

It is need for research, this paper establishes a direct link with the national tax and price levels four indicators of tax rising margin, industrial price index (PPI), household consumption index (CPI) and inflation rate. As the household consumption index is commonly used in China to reflect the inflation rate, so the inflation rate and the consumer price index are equal, we can use the consumer price index on behalf of the inflation rate. For the convenience to application of statistical analysis, the tax rising margin can be set to " $x$ ", the inflation rate is " $y$ "; the indicators were selected the data during 2001-2017, as shown in Table 1. From the data in Table 1, in 2001, the inflation rate isn't easy to be aware of $0.7 \%$, and in 2002 down to $-0.8 \%$, the CPI index was basically flat around the two-year. In 2003, it began to rise and break through price cuts, and in 2004 it drastically increased to $3.9 \%$, people clearly felt the inflationary pressures and worries. And then began to slow down, small fluctuations continuously. But in 2007 , tax rising margin unprecedented increased to $31.4 \%$, and in 2008 continued increasing $18.8 \%$, at the same period the domestic CPI index growth increased $4.5 \%$ and $5.9 \%$, the average exceeded the vicious inflation point. So, whether the price rising promoted the tax rising, or tax rising promoted the price rising?

\subsection{THE Time Series Stationary Test That Tax Interfere Inflation}

Assuming that all data information about tax growth rate $(x)$ and inflation rate $(y)$ are included in the time series, in order to obtain the causal relationship between price rising and tax rising, "Eviews" is used to test the Granger causality to determine whether there is a causal relationship and the direction of the impact from " $x$ " to " $y$ ", the test idea is that if the change of " $x$ " causes the change of " $y$ ", then the change of " $x$ " should happen before " $y$ "; We set confidence or significance level is 0.05 , test value in excess of 0.05 indicates acceptance hypothesis, causality relationship holds; If the test value is lower than this value, it is assumed that the single causal relationship is not established.

Table 1. Tax revenue growth rate and inflation rate from 2001 to 2017.

\begin{tabular}{cccccccccccccccccccc}
\hline Year & 2001 & 2002 & 2003 & 2004 & 2005 & 2006 & 2007 & 2008 & 2009 & 2010 & 2011 & 2012 & 2013 & 2014 & 2015 & 2016 & 2017 \\
\hline $\mathrm{X}(\%)$ & 19.7 & 12.1 & 20.3 & 25.7 & 20 & 21.9 & 31.4 & 18.8 & 9.8 & 22.3 & 22.6 & 15.7 & 8.2 & 8.8 & 6.6 & 4.8 & 5.2 \\
$\mathrm{Y}(\%)$ & 0.7 & -0.8 & 1.2 & 3.9 & 1.8 & 1.5 & 4.8 & 5.9 & -0.7 & 3.3 & 5.4 & 2.6 & 3.2 & 1.5 & 1.4 & 2 & 2.2 \\
$\mathrm{PPI}(\%)$ & -1.3 & -2.2 & 2.3 & 6.1 & 4.9 & 3.0 & 3.1 & 6.9 & 5.4 & 5.5 & 6.0 & -1.7 & -1.9 & -2.8 & -5.2 & 1.3 & \\
\hline
\end{tabular}


According to the relevant index data of test model and Table 1, a highly accurate and efficient test method called Augmented Dickey-Fuller (ADF) was used to test the unit root of $\mathrm{X}$ and $\mathrm{Y}$ time series smoothness. The results are shown in Table 2.

It can be seen from Table 2, the probability value $\mathrm{P}$ of the $\mathrm{X}$-sequence in the first-order difference is much smaller than the significant level of 0.05 , so the original hypothesis can be rejected, that is, the first-order difference of $\mathrm{X}$ that is also called $[D(X)]$ has no unit root, $X$ is stationary of $I(1)$ in the first order differential. And the probability value of the sequence $\mathrm{Y}$ in the original hypothesis of the unit root is less than the significant level of 0.05 , so we reject the original hypothesis. It can be concluded that there is no unit root in the sequence $Y$, the sequence $\mathrm{Y}$ is stationary.

\subsection{Variable Lag Length Test}

The Granger causality test is sensitive to the lag length, and the different lag lengths will produce different test results, depending on the smoothness of the variable or the length of the sample. Therefore, using the Granger causality to test multiple lag lengths that there is no sequence correlation of random interference term in the model, it is shown in Table 3.

From the analysis of Table 3, there is no single causal relationship from the sequence $\mathrm{Y}$ to $\mathrm{X}$ from the lag length 2 to 4 ; there is single causal relationship from $\mathrm{X}$ to $\mathrm{Y}$ for the lag lengths 2 and 3; for the lag length 4, the test " $F$ " statistic

Table 2. Stable tests for the tax rising rate (x) and inflation rate (y).

\begin{tabular}{ccc}
\hline & Level & 1st difference \\
\hline $\mathrm{t}=0.375414$ & $\mathrm{t}=-6.308516$ \\
$\mathrm{P}=0.9735$ & $\mathrm{P}=0.0002$ \\
& (unstable) & (stable) \\
$\mathrm{t}=-3.189386$ & \\
$\mathrm{Y}$ & $\mathrm{P}=0.0412$ & \\
& $($ stable $)$ & \\
\hline
\end{tabular}

Table 3. Granger causality test results for multiple lag lengths.

\begin{tabular}{ccccc}
\hline $\begin{array}{c}\text { The original } \\
\text { hypothesis of the test }\end{array}$ & $\begin{array}{c}\text { The lag } \\
\text { length }\end{array}$ & $\begin{array}{c}\text { "F" Test } \\
\text { statistic }\end{array}$ & $\begin{array}{c}\text { The probability value } \\
\text { of "F" test statistic }\end{array}$ & $\begin{array}{c}\text { Judgments of the original } \\
\text { hypothesis }\end{array}$ \\
\hline$X \nrightarrow Y$ & 2 & 8.14301 & 0.0080 & Reject original hypothesis \\
$Y \nrightarrow X$ & 2 & 3.77267 & 0.0601 & Do not reject original hypothesis \\
$X \nrightarrow Y$ & 3 & 7.05053 & 0.0160 & Reject original hypothesis \\
$Y \nrightarrow X$ & 3 & 2.57639 & 0.1365 & Do not reject original hypothesis \\
$X \nrightarrow Y$ & 4 & 3.39519 & 0.1317 & Do not reject on 5\% level \\
$Y \nrightarrow X$ & 4 & 2.27920 & 0.2223 & Do not reject original hypothesis \\
\hline
\end{tabular}


is not significant at the $5 \%$ test level, therefore it cannot reject the original hypothesis that " $\mathrm{X}$ is not the reason of $\mathrm{Y}$ ". According to the results of the analysis, it can be considered there is single causal relationship from $\mathrm{X}$ to $\mathrm{Y}$, but there is no causal relationship in the opposite direction. In other words, tax revenue is the definite elements that promote the price rising and inflation, and rising prices will not promote tax revenue, during the inflation period the total amount of tax revenue have increased, but its monetary value has not improved, the essence is a number of inflated.

\subsection{Analysis of the Interference of Tax on Inflation}

According to Granger analysis and ADF test results, the tax policy adjustment has a direct impact on the price level, the tax rising rate and inflation rate is not one decrease and the other increase, the two always keep the same trend. According to the indicators in Table 2, we can draw the trend between the two changing relationship, as intuitively shown in Figure 1.

From Figure 1 we can see that the tax revenue rising rate, inflation rate and production price index basically present the same trend. Raising taxes is to increase prices, cutting taxes is to reduce prices. From the overall trend of change, tax revenue and price changes show "three high, three low and one stable" situation. Among them, 2004, 2007, 2010 and three years in the tax revenue and inflation are in high peak, 2005 and 2009 respectively at the bottom, forming a more distinct "W" shape; the beginning of 2010, tax revenue continued to steady after 2012 gradually reduced, then slightly reduced year by year and by 2015 to a minimum, has since been in the stable state, tax revenue and inflation slightly showed "L" shape.

\subsubsection{4, 2007, 2010 Three Consecutive High Peak}

In 2004, the economy increased rapidly, especially the trade surplus made the import tax revenue rising, and increased the tax inspection and the new tax

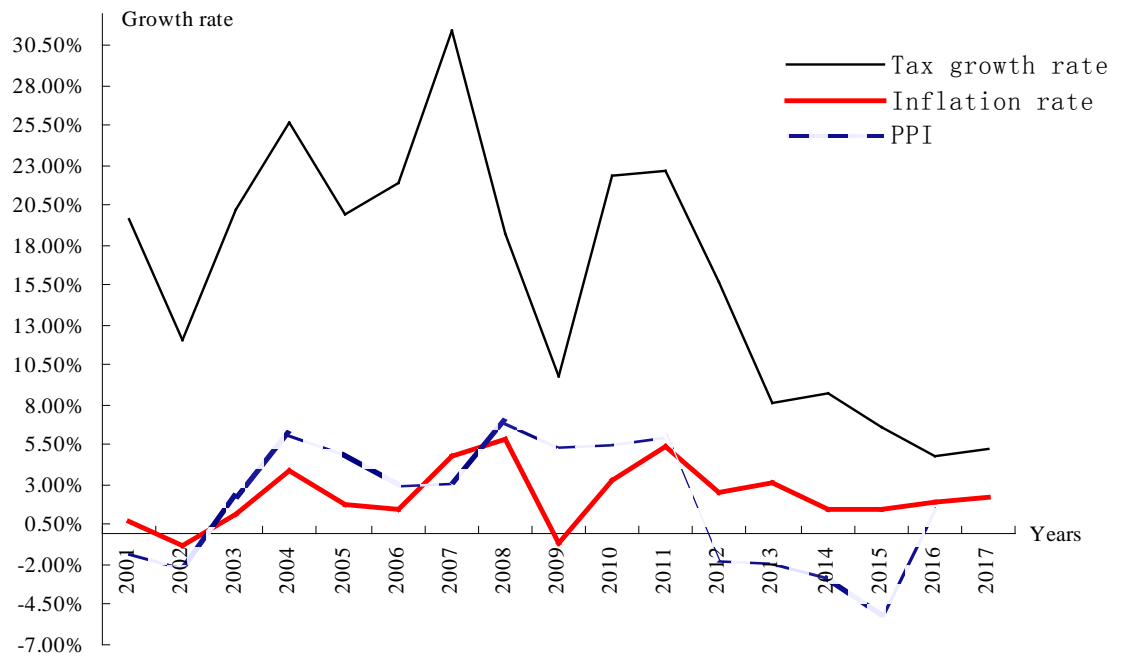

Figure 1. The Impact of tax increase on price and inflation. 
control system to implement the fine management. The tax doubled in 2000, the increased margin was 2.5 times of the GDP growth. With the high tax revenue, the national CPI index from April appeared a big increased margin. They are all breaking $5 \%$ during the four month from June to September. The inflation is very obvious.

2007 the stamp duty increased with leaps and bounds from 1\%o to 3\%o and caused the stock market plummeting called " 5.30 ". In order to greet the 2008 new corporate income tax law, it increased to clean up about corporate income tax, the real estate prices increased menacing to make it an increase of $36.6 \%$, business tax increased more crazy $40.3 \%$, tax revenue almost equal to 5 trillion yuan, an increase of $31.4 \%$; The CPI, which has not yet included real estate consumption, jumped from $1.5 \%$ in the previous year to $4.8 \%$, up 3.3 percentage points, higher than the government's $3 \%$ index, of which $31.7 \%$ were poultry and its products, it was known as "inflation year" and the situation until the peak in 2008 before the fall. From the trend of production price index change, because of the US subprime mortgage crisis in 2008, the domestic consumption value-added tax pilot expansion and other major events, especially in 2009 it began to implement fully the consumer value-added tax reform, the production prices continued stabilizing to the Transition from Business Tax to Value-Added Tax (VAT) of 2012.

In 2010 it is high growth, because of the influence in 2009 "consumer value-added tax", the whole society increased the scale of fixed asset investment and promoted the rapid growth of industrial economy, the tax increased significantly, while the price jumped from the trough of $-0.7 \%$ to $3.3 \%$. It can be called the most increase more than ten years; the tax continued to grow steadily in 2011, the price continued to heat up till the peak. It was stable later and came down step by step.

\subsubsection{2, 2009, 2013 Three Years of Low}

On December 11, 2001 China officially entered the WTO as the 143rd member of the WTO, following the "Western Development" strategy to established a "consumer value-added tax" on trail once again as the main line of the "northeast old industrial base" revitalization plan, under the situation that GDP increase continued to rise, the state tax does not increase, the CPI index fell sharply, many years the "negative growth" appeared rarely for many years; With the US subprime mortgage crisis and the financial crisis affecting the domestic economic development, GDP and fiscal revenue have dropped significantly for two consecutive years, combined with a comprehensive reform of corporate income tax from $33 \%$ leap to $25 \%$, in early December 2008 the central economic work meeting put forward "structural tax reduction" strategy firstly, from 2009 the consumer value-added tax would be fully implemented, the national tax revenue for two consecutive years reduced more than 10 percentage points or even more times, the price level also slid down to "freezing point" once again; After 2013 the country seized the opportunity of economic downturn to promote the 
"business increase" and small micro-enterprises implementing value-added tax and income tax concessions, equipment manufacturing industry fixed assets depreciation policy and so on, accelerated supply-side reform for the development of structural reduction tax. Tax increases and inflation rate gradually decreased and ran smoothly, it formed "L" type trend echoed of which compared with 2011.

\section{Conclusion and Suggestion}

The study shows that there is single causal relationship between the tax on the price; that is, the tax rising will directly promote the price rising, and the price rising will not bring substantial increase in national tax revenue; there is the same trend between government taxation and price increase or decrease. In other words, if the government increases the taxes, the market price will increase, and then the inflation will produce with it. Conversely, if the government implements the low tax, tax reduction policy, the price will fall accordingly and inhibit inflation [7]. It can be seen that the relationship between taxation and inflation is expressed as follows: government plus (minus) tax $\rightarrow$ commodity price (decrease) price $\rightarrow$ consumption increase (decrease) negative $\rightarrow$ price rise (decrease) $\rightarrow$ inflation (tightening). This is also the basic path of tax impact on inflation. The "tax-based inflation" under the responsibility of the government also can be achieved by governance effects through the policy adjustment, such as to adjust the tax object and scope, reduce tax rates or tax concessions, promote the supply side of the structural reform, enhance supply capacity, realize the effective suppression.

At the same time, it is recommended that when formulating a tax reform policy, the government must not only consider financial needs but also take into account the risk of inflation interference. To accelerate the construction of social and economic undertakings at the peacetime, more concerns about the improvement of the people's market environment and the quality of life should be taken. It can definitely not add new taxes in non-special period of special needs of the production and circulation, nor can excessively increase in value-added tax rate to prevent triggering inflation sensitivity.

In addition, we should further explore new measures to reduce the turnover tax, gradually cancel the additional taxes and increase the corporate income tax new system, reduce the pressure that the turnover tax shifts to the market price, and decrease the tax on the behavior of excessive interference with inflation, by taking the local economic development, the transformation and development of the resource-based cities, the development of key areas and the environmental protection as the goal.

The important contribution of this research is to present and prove an important view that increasing taxes by the government will push prices up and cause inflation. At the same time, we actively advocate that during the period of sustained inflation, the government should increase the value by lowering the tax 
revenue, especially reducing the turnover taxes to effectively contain inflation and stabilize prices. The subject of the limitations of historical data, the empirical analysis of this article is also somewhat simplistic, which may lead to a certain impact on the convincing level of the conclusion.

\section{Acknowledgements}

During the course of this study, I would like to thank the graduate team of the Accounting School in Heilongjiang Bayi Agriculture University for their support and assistance in data processing and project proofreading. Especially, I would like to thank the Heilongjiang Province Land Reclamation Bureau of key research topics "Reclamation of modern agriculture development elements and evaluation index system" (HNK125B-14-04) for its support and help. Thanks to the careful evaluation and guidance which play an important role in modifying the contents and extracting the viewpoints of all review experts. The article quotes the excellent research achievements of the predecessors. Please forgive for no comments. I am here to give consistent thanks.

\section{Funding}

Fund Source: Heilongjiang Province Land Reclamation Bureau of key research topics "Reclamation of modern agriculture development elements and evaluation index system" (HNK125B-14-04).

Wang Shufeng (1963.7-): Male, native of Jilin Jiutai, Heilongjiang Bayi Agriculture University Accounting of Finance and Auditing Professor, Master Instructor, senior member of China Accounting Institute. The main research direction: audit theory and practice, tax economy and tax accounting.

\section{References}

[1] Zhang, Y.G. and Cai, Z.Y. (1989) Taxation and Inflation. Finance and Economics, 7, 31-34.

[2] Li, J.H. (2011) The Impact of Rising Prices on China's Tax Revenue-From the Current Round of Price Increases. Xinjiang Finance, 6, 56-59.

[3] Li, M.Q. (2013) The Formation of Liquidity in China under the Constraints of Liquidity and the Impact of Inflation. Jilin University, Jilin.

[4] Zhu, C.Y. (2005) Comparison of Western Mainstream Income Distribution Theory and Marx's Theory of Income Distribution. Shandong Social Sciences, 2, 120-122.

[5] Liu, H.Z. (2013) Granger Pseudo Causality Test Based on HAC Estimation. Journal of Systems Engineering and Practice, 8, 105-112. (In Chinese with English Abstract)

[6] China's Tobacco Industry Adjusts Consumption Taxes to Increase Production of Tobacco by 2015. http://www.chinabgao.com/info/81688.html

[7] Wang, L.J. (2014) On the Role of Price Adjustment Fund in Market Economy. Enterprises Economics and Management, 5, 12-13. 